\title{
Fournier's gangrene: etiology, treatment outcomes and factors affecting mortality in 38 patients
}

\author{
Murat Derebey $^{1}$, Ismail Alper Tarim $^{1}$, Ufuk Karabacak $^{2}$ Kadir Seker $^{3}$, Gokhan Selcuk \\ Ozbalci ${ }^{1}$
}

${ }^{1}$ Department of General Surgery, Ondokuz Mayis University, Faculty of Medicine, Samsun, Turkey

${ }^{2}$ Department of Surgical Oncology, Sivas Cumhuriyet University, Faculty of Medicine, Sivas, Turkey

${ }^{3}$ Department of General Surgery, Bafra State Hospital, Samsun, Turkey

\begin{abstract}
Aim: Fournier's gangrene (FG) is a rare, rapidly progressing and life-threatening disease of the genital, perianal and perineal regions. We aimed to evaluate etiological parameters, accompanying diseases, current treatment methods and factors affecting mortality in patients with FG.

Method: The medical records of 38 patients who were operated by the same team with a diagnosis of FG from December 2015 to January 2021 were retrospectively reviewed. Those patients were divided into two groups: survivors (Group 1), and non-survivors (Group 2). Comparisons were made regarding clinical and demographic features; comorbid diseases; leukocyte count at first presentation; etiological factors; treatment outcomes; and mortality rates.

Results: Thirty-eight patients (24 males, 14 females) were evaluated; mean age was $60.2 \pm 13.2$ years. While $76.3 \%(n=29)$ of these patients recovered with treatment, the total mortality rate was $23.7 \%(n=9)$. The most common cause of the FG and comorbidity were anorectal diseases $(n=22 ; 57.9 \%)$ and type 2 diabetes mellitus ( $\mathrm{n}=21 ; 55.3 \%$ ), respectively. Female gender, septic shock, necrosis, abdominal wall and lumbar region involvement, chronic renal failure, FG development secondary to postoperative complications and ostomy rates were higher in non-survivors. There were no significant differences between the two groups regarding leukocyte count at first presentation, number of debridement, dressing methods, reconstruction methods, and length of hospital stay.
\end{abstract}

Conclusions: Female gender, presence of septic shock and necrosis on physical examination, involvement of the abdominal wall and lumbar region in addition to the perianal region, chronic renal failure, disease secondary to postoperative complications and the necessity of ostomy play an important role in mortality.

Key words: Fournier's gangrene, etiology, therapy, outcome, mortality.

$\triangle$ Dr. Murat Derebey

Department of General Surgery, Ondokuz Mayis

University, Faculty of Medicine, Samsun, Turkey

E-mail: mderebey@gmail.com

Received: 2021-02-28 / Revisions: 2021-04-20

Accepted: 2021-04-29 / Published online: 2021-07-01

\section{Introduction}

In 1883, Dr Jean Alfred Fournier described an infection with unknown origin that led to rapid necrosis of the scrotal skin in young healthy men [1]. This infection is now called Fournier's gangrene (FG), although other definitions have been proposed, such as necrotising fasciitis, as suggested by Wilson in 1952 [2]. The term FG is now more widely implemented to genital, perianal, perirectal and abdominal wall infections. Although the initial definition does not contain a known etiology, trauma and 
infection of the perianal and genital areas seem to play an important role in this disease [3]. FG can occur after colorectal and urinary system pathologies, perineal infections, perianal or genital trauma and any surgical intervention in the above-mentioned areas. This disease, which appears suddenly and progresses rapidly, is mostly mortal if not it is under control with early treatment $[4,5]$. It can affect both genders and individuals in all ages [6].

Predisposing factors include diabetes mellitus, hypertension, coronary and peripheral artery diseases, obesity, smoking, drug addiction, poor hygiene, chronic alcoholism, malignancies and immunosuppression [7, 8]. This disease, which is difficult to diagnose without necrosis or gangrene, can show a rapid course and lead to death [9]. Early diagnosis of FG and determining the correct treatment method are very important for survival. The emergency treatment of FG begins with surgical debridement and broad-spectrum antibiotic therapy [3]. After the initial comprehensive debridement, a series of repetitive debridement may be required. An effective dressing is very valuable in treatment. In recent years, negative pressure wound therapy (NPWT) has gained popularity and is widely used in wound management [10].

Despite the advancement of knowledge on etiology, diagnosis, treatment and intensive care techniques, the mortality rate of FG patients is still high. The incidence of FG is increasing especially in developed countries aging population. Therefore, it is important to understand the predisposing factors, pathophysiology and clinical course of this disease. In this study, we aimed to review our experiences of FG treatment and to evaluate the etiological parameters, accompanying diseases, current treatment methods and factors affecting mortality in patients with FG.

\section{Materials and methods}

Ethical approval was obtained from the Local Ethics Committee for this study (IRB approval number OMU: 2020/751). The medical records of 38 patients who were operated by the same team with a diagnosis of FG from December 2015 to January 2021 were retrospectively reviewed. The diagnosis of FG was established based on patient history, clinical symptoms, physical examination at presentation and radiological findings.

The patients were divided into two groups as follows: survivors (Group 1, $\mathrm{n}=29$ ) and nonsurvivors (Group 2, $\mathrm{n}=9$ ). Demographic characteristics of the patients, initial symptoms, involved areas, etiological factors, comorbidities, leukocyte count at first presentation, number of debridement, dressing methods (wet or negative aspiration system), the presence of a diverting ostomy, reconstruction methods, and length of hospital stay were recorded and compared between the two groups. The effect of these parameters on clinical results was investigated.

All data were analyzed by using SPSS (Statistical Package for Social Sciences) for Windows 15.0 program. In the comparison of qualitative data, descriptive statistical methods (mean or median and standard deviation) and Pearson's chi-square test were used. The MannWhitney U test and independent samples t-test were used for binary comparisons of continuous variables. A value of $p<0.05$ was accepted as statistically significant.

\section{Results}

Thirty-eight patients who were operated by the same team for FG were included in this study. While $29(76.3 \%)$ of these patients recovered with treatment, $9(23.7 \%)$ patients were deceased. Data on patient age, gender, clinical features, leukocyte count at first presentation 
Table 1. Patient demographics, clinical features, leukocyte count at first presentation and comorbid diseases

\begin{tabular}{|c|c|c|c|c|}
\hline Parameters & $\begin{array}{c}\text { Group I } \\
(\mathrm{n}=29)\end{array}$ & $\begin{array}{c}\text { Group II } \\
(\mathrm{n}=9)\end{array}$ & $\begin{array}{c}\text { Total } \\
(\mathrm{n}=38)\end{array}$ & P value \\
\hline Age $^{*}$ (years) & $59.5(12.9)$ & $62.5(14.6)$ & $60.2(13.2)$ & .559 \\
\hline \multicolumn{5}{|l|}{ Gender } \\
\hline Female & $8(27.6 \%)$ & $6(66.7 \%)$ & $14(36.8 \%)$ & \multirow{2}{*}{.034} \\
\hline Male & $21(72.4 \%)$ & $3(33.3 \%)$ & $24(63.2 \%)$ & \\
\hline \multicolumn{5}{|l|}{ Initial symptoms } \\
\hline Perianal swelling & $22(75.9 \%)$ & $2(22.2 \%)$ & $24(63.2 \%)$ & .040 \\
\hline Perianal pain & $20(69 \%)$ & $1(11.1 \%)$ & $21(55.3 \%)$ & .002 \\
\hline Necrosis & $9(31 \%)$ & $8(88.9 \%)$ & $17(44.7 \%)$ & .002 \\
\hline Fever & $11(37.9 \%)$ & $1(11.1 \%)$ & $12(31.6 \%)$ & .130 \\
\hline Perineal pain & $9(31 \%)$ & $1(11.1 \%)$ & $10(26.3 \%)$ & .236 \\
\hline Crepitus & $7(24.1 \%)$ & $3(33.3 \%)$ & $10(26.3 \%)$ & .584 \\
\hline Septic shock & $1(3.4 \%)$ & $6(66.7 \%)$ & $7(18.4 \%)$ & $<.001$ \\
\hline Scrotal swelling & $5(17.2 \%)$ & $2(22.2 \%)$ & $7(18.4 \%)$ & .736 \\
\hline Vulvar swelling & $3(10.3 \%)$ & $2(22.2 \%)$ & $5(13.2 \%)$ & .689 \\
\hline \multicolumn{5}{|l|}{ Involved area } \\
\hline Perianal & $24(82.8 \%)$ & $4(44.4 \%)$ & $28(73.7 \%)$ & .023 \\
\hline Genital & $14(48.3 \%)$ & $4(44.4 \%)$ & $18(47.4 \%)$ & .841 \\
\hline Perineal & $14(48.3 \%)$ & $3(33.3 \%)$ & $17(44.7 \%)$ & .431 \\
\hline Abdominal wall & $4(13.8 \%)$ & $7(77.8 \%)$ & $11(28.9 \%)$ & $<.001$ \\
\hline Lumbar region & $4(13.8 \%)$ & $4(44.4 \%)$ & $8(21.1 \%)$ & .049 \\
\hline \multicolumn{5}{|l|}{ Etiology } \\
\hline Anorectal & $19(65.5 \%)$ & $3(33.3 \%)$ & $22(57.9 \%)$ & .088 \\
\hline Urogenital & $3(10.3 \%)$ & $3(33.3 \%)$ & $6(15.8 \%)$ & .098 \\
\hline Cutaneous & $4(13.8 \%)$ & 0 & $4(10.5 \%)$ & .239 \\
\hline Postoperative complication & $1(3.4 \%)$ & $3(33.3 \%)$ & $4(10.5 \%)$ & .011 \\
\hline Trauma & $2(6.9 \%)$ & 0 & $2(5.3 \%)$ & .418 \\
\hline COVID-19 & $1(3.4 \%)$ & 0 & $1(2.6 \%)$ & .572 \\
\hline $\begin{array}{l}\text { Leukocyte count at first } \\
\text { presentation* }(u / L)\end{array}$ & 17047 (7336) & $16735(8206)$ & $16973(7436)$ & .914 \\
\hline \multicolumn{5}{|l|}{ Comorbid disease } \\
\hline Diabetes & $17(58.6 \%)$ & $4(44.4 \%)$ & $21(55.3 \%)$ & .455 \\
\hline Hypertension & $7(24.1 \%)$ & $4(44.4 \%)$ & $11(28.9 \%)$ & .241 \\
\hline Coronary artery disease & $7(24.1 \%)$ & $2(22.2 \%)$ & $9(23.7 \%)$ & .906 \\
\hline Malignancy & $5(17.2 \%)$ & $3(33.3 \%)$ & $8(21.1 \%)$ & .301 \\
\hline Chronic renal failure & $2(6.9 \%)$ & $3(33.3 \%)$ & $5(13.2 \%)$ & .040 \\
\hline Cerebrovascular disease & $3(10.3 \%)$ & $2(22.2 \%)$ & $5(13.2 \%)$ & .357 \\
\hline
\end{tabular}

*Data is presented as mean (standard deviation), Bold values indicate statistical significance. 
Table 2. The etiology of Fournier's gangrene.

\begin{tabular}{|l|l|l|l|}
\hline Etiology & Group I & Group II & Total \\
\hline Anorectal & $19(50 \%)$ & $3(7.9 \%)$ & $22(57.9 \%)$ \\
\hline Perianal abscess & $10(26.5 \%)$ & $1(2.6 \%)$ & $11(29.1 \%)$ \\
\hline Fistula to the rectum & $1(2.6 \%)$ & - & $1(2.6 \%)$ \\
\hline Ischiorectal abscess & $4(10.5 \%)$ & - & $4(10.5 \%)$ \\
\hline Perforated appendicitis & $1(2.6 \%)$ & - & $1(2.6 \%)$ \\
\hline Rectum cancer & $1(2.6 \%)$ & - & $1(2.6 \%)$ \\
\hline Perforated cecum tumor & - & $1(2.6 \%)$ & $1(2.6 \%)$ \\
\hline Rectum perforation / foreign body & $1(2.6 \%)$ & - & $1(2.6 \%)$ \\
\hline Diverticular perforation & $1(2.6 \%)$ & $1(2.6 \%)$ & $2(5.3 \%)$ \\
\hline Urogenital & $3(7.9 \%)$ & $3(7.9 \%)$ & $6(15.8 \%)$ \\
\hline Scrotal abscess & $1(2.6 \%)$ & $1(2.6 \%)$ & $2(5.3 \%)$ \\
\hline Vulvar abscess & $1(2.6 \%)$ & $2(5.3 \%)$ & $3(7.9 \%)$ \\
\hline Bartholin abscess & $1(2.6 \%)$ & - & $1(2.6 \%)$ \\
\hline Cutaneous & $4(10.5 \%)$ & 0 & $4(10.5 \%)$ \\
\hline Decubitus ulcer & $2(5.3 \%)$ & - & $2(5.3 \%)$ \\
\hline Perineal soft tissue infection & $2(5.3 \%)$ & - & $2(5.3 \%)$ \\
\hline Postoperative complication & $1(2.6 \%)$ & $3(7.9 \%)$ & $4(10.5 \%)$ \\
\hline Haemorrhoidal disease & $1(2.6 \%)$ & - & $1(2.6 \%)$ \\
\hline Intestinal anastomotic leak & - & $2(5.3 \%)$ & $2(5.3 \%)$ \\
\hline Colostomy complication & - & $1(2.6 \%)$ & $1(2.6 \%)$ \\
\hline Trauma & $2(5.3 \%)$ & 0 & $2(5.3 \%)$ \\
\hline COVID-19 & $1(2.6 \%)$ & 0 & $1(2.6 \%)$ \\
\hline
\end{tabular}

Table 3. Treatment outcomes for Fournier's gangrene.

\begin{tabular}{|c|c|c|c|c|}
\hline Parameters & Group I $(n=29)$ & Group II $(n=9)$ & Total $(n=38)$ & P value \\
\hline Number of debridement* & $3(2-20)$ & $3(2-12)$ & $3(2-20)$ & .927 \\
\hline \multicolumn{5}{|l|}{ Dressing methods } \\
\hline \multirow{2}{*}{$\begin{array}{l}\text { Wet-dressing } \\
\text { NPWT }\end{array}$} & $4(13.8 \%)$ & 0 & & \multirow[b]{2}{*}{.266} \\
\hline & $25(86.2 \%)$ & $9(100 \%)$ & $34(89.5 \%)$ & \\
\hline Ostomy & $8(27.6 \%)$ & $6(66.7 \%)$ & $14(36.8 \%)$ & .034 \\
\hline \multicolumn{5}{|l|}{ Reconstruction } \\
\hline Fasciocutaneous flap & $4(13.8 \%)$ & $2(22.2 \%)$ & $6(15.8 \%)$ & \multirow{2}{*}{.203} \\
\hline Split-thickness skin graft & $8(27.6 \%)$ & 0 & $8(21.1 \%)$ & \\
\hline Length of hospital stay (day) & $23(3-59)$ & $20(4-86)$ & $22(3-86)$ & .447 \\
\hline
\end{tabular}

NPWT: negative pressure wound therapy, *Data is presented as median (min-max value), Bold value indicate statistical significance. 
and comorbid diseases are presented in Table 1. The mean age was $60.2 \pm 13.2$ years and $63.2 \%$ of the population was male. Female gender was significantly higher in Group $2(p<0.05)$.

When the initial symptoms were compared, perianal swelling and perianal pain were significantly higher in Group 1, and septic shock and necrosis in Group $2(p<0.05)$. Perianal involvement was more common in Group 1 and abdominal wall and lumbar region involvement in Group 2 ( $p<0.05)$.

Etiological origins are shown in Table 1 and Table 2, and the most common cause of Fournier's gangrene was a perianal or perirectal infection spreading to the perineum, external urogenital organs, abdominal wall, and lumbar region. FG developing secondary to postoperative complications was significantly higher in Group 2 ( $p<0.05)$. There was no statistical difference between the groups in terms of leukocyte count at first presentation. The most common comorbid disease was diabetes mellitus (21 patients; $55.3 \%$ ). $33 \%$ of the patients who died from Fournier's gangrene had chronic renal failure. In Group 1, Fournier's gangrene occurred in 1 patient during COVID 19 treatment and in 2 patients after blunt perineal trauma due to falling from height (Table 2).

There were no significant differences between the two groups regarding number of debridement, dressing methods, reconstruction methods, and length of hospital stay ( $p>0.05)$. Ostomy was required in $8(27.6 \%)$ patients in Group 1 and $6(66.7 \%)$ patients in Group 2 due to anal sphincter defect or surgical wound contamination. Stoma rate was higher in Group 2 ( $p<0.05)$ (Table 3).

\section{Discussion}

Fournier's gangrene (FG) is a rare but serious and progressive infection that can affect the genital area, perineum and lower abdominal wall separately or together [3]. As the causative microorganisms multiply, the infection spreads to the anatomical fascial planes. The pathognomonic histological findings on FG are necrosis of the superficial and deep fascial planes, fibrin deposition within and around the arterioles [11]. FG predominantly occurs in individuals aged between 30 and 60 [12]. In a recent study, although this disease is detected at all ages, it has been reported mostly in individuals in their fifties [13]. This aggressive disease process is associated with a high mortality rate of $20-30 \%$ [14]. There are different results in the literature regarding age as a prognostic factor for death. Sorensen et al. [15] emphasized that the prognosis worsens with increasing patient age, while Yeniyol et al. [16] found no statistical difference in age between survivors and non-survivors. The mean age of the patients in the present study was 60.2 years and the mortality rate was $23.7 \%$. We did not observe any significant difference in age among groups. While FG has been known to be a predominantly male disease since scrotal involvement was used as the key component of the original FG definition, the definition has expanded with the presentation of this disease also in women [17]. Although FG was observed less frequently in women in our study, the mortality rate was found to be significantly higher. Similarly, Czymek et al. [18] stated that female gender is a prognostic factor for mortality. On the other hand, this result may be due to the fact that the study was conducted with a smaller number of patients.

Patients usually come to the emergency service within a few days after the onset of complaints such as purulent rectal discharge, perineal edema or pain. Infectious sources are mostly anorectal diseases, urological diseases, intraperitoneal events or traumatic injuries, and 
in some cases the cause may not be determined $[19,20]$. In this study, the main patient complaints were perianal swelling, perianal pain, and necrosis around the anus. The mortality rate was significantly higher in patients who had symptoms of necrosis and septic shock at presentation, and accompanying abdominal wall and lumbar region involvement in addition to perianal involvement. Although many diseases have been reported to be positively associated with FG, especially diabetes mellitus is the most important predisposing factor among them [3, 21]. On the other hand, the relationship between diabetes mellitus and mortality is still controversial. Some studies report an association with both incidence and mortality, while others only show a relationship with incidence. In our study, $55.3 \%$ of the patients had diabetes mellitus; however, there was no significant association between diabetes mellitus and mortality. In a recent study, FG with extensive soft tissue necrosis and pre-existing chronic kidney disease was associated with poor prognosis [22]. Similarly, chronic renal failure was statistically more common in non-survivors in this study.

Previously, FG was generally known as a urological disease, but now it is mainly of concern to general surgeons as the most common etiology is colorectal-derived diseases. Stephens et al. found a higher mortality in patients with colorectal-derived FG compared to other etiologies [23]. Necrotizing soft tissue infections caused by intestinal perforation can occur in an atypical fashion with significant morbidity and mortality rates [24]. When anorectal etiologies and postoperative colorectal surgery complications were evaluated together, it was seen that they constituted $68.4 \%$ of the total etiology in our study. Moreover, mortality rate was high in FG cases developing secondary to postoperative colorectal surgery complications. Fournier's gangrene was detected in a 76-year-old female patient who was followed up in the intensive care unit due to respiratory failure secondary to COVID-19. COVID-19, which suppresses the immune system, has emerged as another etiological factor. The above mentioned patient, who underwent emergency and aggressive debridement along with COVID-19 treatment, was discharged on the 7th week of hospitalization. It has been reported that a high mean leukocyte count at first presentation is a prognostic factor for mortality [25]. On the contrary, no significant difference was found among the groups in terms of leukocyte count in our study.

Early diagnosis, urgent debridement and adequate administration of broad-spectrum antibiotics are the most essential component of treatment [26]. In this study, aggressive debridement and broad-spectrum antibiotic therapy were performed to all patients. Serial debridement was continued until necrotic lesions disappeared at the wound site. The median amount of debridement for both groups was 3 and there was no statistically significant difference between the groups. A conventional wet-to-dry dressing is a well-known, popular, inexpensive and accepted method with many advantages such as keeping the wound clean. NPWT is a widely used another method of wound treatment [27]. Once the necrosis is eliminated, NPWT helps the wound heal physiologically. The negative pressure leads to increased blood flow and the migration of inflammatory cells to into the wound site [28]. NPWT requires less frequent change compared to traditional dressings and is a less painful procedure. This also prevents bacterial contamination and accelerates the formation of granulation tissue with the removal of exudates 
[29,30]. NPWT treatment was used in $89.5 \%$ of all patients, and there was no statistically significant difference between the groups in terms of wound therapy.

The debridement area usually carries the risk of faecal contamination [31]. Therefore, a faecal diversion is an important attempt at FG treatment. Loop colostomy is often used in patients with severe perineal involvement and wounds close to the anus [32]. The literature has shown that patients requiring ostomy has a poor prognosis [15]. $36.8 \%$ of the patients required ostomy and there was statistically significant association between ostomy and prognosis. Stoma rate was statistically higher in non-survivors. Early closure of tissue defects is an important part of treatment. Various reconstructive methods are available for good functional and cosmetic results. There is no consensus on the best method of reconstruction. The reconstructive treatment should be based on the patient's clinical characteristics, patient preference, and surgeon's judgment [33]. We preferred either fasciocutaneous flap or splitthickness skin graft in wounds with large tissue defects that did not close with secondary healing after NPWT treatment. Major wounds caused by debridement in FG patients usually take a long time to heal and thus require a long hospital stay. Although Ersay et al. [20] have determined that longer hospital stay was a factor affecting survival, there was no statistically significant difference between the groups in terms of hospital stay in our study.

The limitation of this study was associated with the disadvantages caused by the retrospective design. Although the data were collected in a five-year period, the sample size was small. Another limitation was that when the patient data were analyzed retrospectively, we could not reach all the necessary laboratory values to calculate the FGSI score. Therefore, we could not use this parameter to compare between groups. FG with diffuse soft tissue necrosis is associated with poor prognosis and complex patient management. Rapid recognition of disease spread and patient's poor prognostic factors is essential to reduce mortality and establish a management plan for this disease. In spite of development in medical treatment and intensive care procedures, FG is still a mortal disease.

\section{Conclusion}

Fournier's gangrene is a serious surgical emergency with a high mortality rate. Female gender, presence of septic shock and necrosis on physical examination, involvement of the abdominal wall and lumbar region in addition to the perianal region, chronic renal failure, disease secondary to postoperative complications and the necessity of ostomy play an important role in mortality.

Funding: The author(s) received no financial support for the research, authorship, and/or publication of this article.

Conflict of Interest: The authors declare that they have no conflict of interest.

Ethical statement: The study was approved by the Local Ethics Committee of Ondokuz Mayis University (IRB approval number OMU: 2020/751), and written informed consent was obtained from each subject.

\section{Open Access Statement}

This is an open access journal which means that all content is freely available without charge to the user or his/her institution under the terms of the Creative Commons Attribution NonCommercial License (http://creativecommons.org/licenses/bync/4.0). Users are allowed to read, download, copy, distribute, print, search, or link to the full 
texts of the articles, without asking prior permission from the publisher or the author.

\section{References}

[1]Fournier JA. Jean-Alfred Fournier 18321914. Gangrène foudroyante de la verge (overwhelming gangrene). Sem Med 1883. Diseases of the colon and rectum. 1988;31(12):984-88.

[2]Wilson B. Necrotizing fasciitis. The American surgeon. 1952;18(4):416-31.

[3]Morpurgo E, Galandiuk S. Fournier's gangrene. The Surgical clinics of North America. 2002;82(6):1213-24.

[4]Korhonen K. Hyperbaric oxygen therapy in acute necrotizing infections with a special reference to the effects on tissue gas tensions. Annales chirurgiae et gynaecologiae Supplementum. 2000(214):7-36.

[5]Eke N, Echem RC, Elenwo SN. Fournier's gangrene in Nigeria: a review of 21 consecutive patients. International surgery. 2000;85(1):77-81.

[6]Oguz A, Gümüş M, Turkoglu A, et al. Fournier's Gangrene: A Summary of 10 Years of Clinical Experience. International surgery. 2015;100(5):934-41.

[7]Hejase MJ, Simonin JE, Bihrle R, et al. Genital Fournier's gangrene: experience with 38 patients. Urology. 1996;47(5):73439.

[8]Benizri E, Fabiani P, Migliori G, et al. Gangrene of the perineum. Urology. 1996;47(6):935-39.

[9]Jeong HJ, Park SC, Seo IY, et al. Prognostic factors in Fournier gangrene. International journal of urology : official journal of the Japanese Urological Association. 2005;12(12):1041-44.

[10] Pour SM. Use of negative pressure wound therapy with silver base dressing for necrotizing fasciitis. Journal of wound, ostomy, and continence nursing : official publication of The Wound, Ostomy and Continence Nurses Society. 2011;38(4):44952.

[11] Vick R, Carson CC, 3rd. Fournier's disease. The Urologic clinics of North America. 1999;26(4):841-49.

[12] Sockkalingam VS, Subburayan E, Velu E, et al. Fournier's gangrene: prospective study of 34 patients in South Indian population and treatment strategies. Pan African medical journal. 2018;12(31):110.

[13]Bilton BD, Zibari GB, McMillan RW, et al. Aggressive surgical management of necrotizing fasciitis serves to decrease mortality: a retrospective study. The American surgeon. 1998;64(5):397-400.

[14] Singh A, Ahmed K, Aydin A, et al. Fournier's gangrene. A clinical review. Archivio italiano di urologia, andrologia : organo ufficiale [di] Societa italiana di ecografia urologica e nefrologica. 2016;88(3):157-64.

[15] Sorensen MD, Krieger JN, Rivara FP, et al. Fournier's gangrene: management and mortality predictors in a population based study. The Journal of urology. 2009;182(6):2742-47.

[16] Yeniyol CO, Suelozgen T, Arslan M, et al. Fournier's gangrene: experience with 25 patients and use of Fournier's gangrene severity index score. Urology. 2004;64(2):218-22.

[17] Smith GL, Bunker CB, Dinneen MD. Fournier's gangrene. British journal of urology. 1998;81(3):347-55.

[18] Czymek R, Frank P, Limmer S, et al. Fournier's gangrene: is the female gender a risk factor? Langenbecks Arch Surg. 2010;395(2):173-80. 
[19] Shyam DC, Rapsang AG. Fournier's gangrene. The surgeon : journal of the Royal Colleges of Surgeons of Edinburgh and Ireland. 2013;11(4):222-32.

[20]Ersay A, Yilmaz G, Akgun Y, et al. Factors affecting mortality of Fournier's gangrene: review of 70 patients. ANZ journal of surgery. 2007;77(1-2):43-48.

[21] Taviloglu K, Yanar H. Necrotizing fasciitis: strategies for diagnosis and management. World Journal of Emergency Surgery. 2007;2(1):19.

[22]Hahn HM, Jeong KS, Park DH, et al. Analysis of prognostic factors affecting poor outcomes in 41 cases of Fournier gangrene. Annals of surgical treatment and research. 2018;95(6):324-32.

[23]Enriquez JM, Moreno S, Devesa M, et al. Fournier's syndrome of urogenital and anorectal origin. A retrospective, comparative study. Diseases of the colon and rectum. 1987;30(1):33-37.

[24]Kumar D, Cortés-Penfield NW, El-Haddad $\mathrm{H}$, et al. Bowel Perforation Resulting in Necrotizing Soft-Tissue Infection of the Abdomen, Flank, and Lower Extremities. Surgical infections. 2018;19(5):467-72.

[25] Villanueva-Sáenz E, Martínez HernándezMagro P, Valdés Ovalle M, et al. Experience in management of Fournier's gangrene. Techniques in coloproctology. 2002;6(1):510.

[26] Norton KS, Johnson LW, Perry T, et al. Management of Fournier's gangrene: an eleven year retrospective analysis of early recognition, diagnosis, and treatment. The American surgeon. 2002;68(8):709-13.

[27] Ozturk E, Ozguc H, Yilmazlar T. The use of vacuum assisted closure therapy in the management of Fournier's Gangrene. American journal of surgery. 2009;197(5):660-65.
[28] Arslan E, Ozturk OG, Aksoy A, et al. Vacuum-assisted closure therapy leads to an increase in plasma fibronectin level. International wound journal. 2011;8(3):22428.

[29] Assenza M, Cozza V, Sacco E, et al. VAC (Vacuum Assisted Closure) treatment in Fournier's gangrene: personal experience and literature review. La Clinica terapeutica. 2011;162(1):e1-5.

[30]Czymek R, Schmidt A, Eckmann C, et al. Fournier's gangrene: vacuum-assisted closure versus conventional dressings. American journal of surgery. 2009;197(2):168-76.

[31]Ozkan OF, Altýnlý E, Koksal N, et al. Combining Flexi-Seal and negative pressure wound therapy for wound management in Fournier's gangrene. International wound journal. 2015;12(3):364-5.

[32] Ozkan OF, Koksal N, Altinli E, et al. Fournier's gangrene current approaches. International wound journal. 2016;13(5):713-16.

[33] Insua-Pereira I, Ferreira PC, Teixeira S, et al. Fournier's gangrene: a review of reconstructive options. Central European journal of urology. 2020;73(1):74-79. 